\title{
Infection status of hydatid cysts in Iran: A review
}

\author{
Faham Khamesipour, ${ }^{1}$ Shadan Shojaat, ${ }^{1}$ Bahareh Basirpour, ${ }^{2}$ Parya Kheiri, ${ }^{1}$ Sana-Sadat Afzal, ${ }^{1}$ \\ Bahar Chelgerdi, ${ }^{1}$ Saeed Nezaratizadeh, ${ }^{1}$ Seyed-Hossein Hejazi ${ }^{2,3}$ \\ ${ }^{1}$ Shahrekord Branch, Islamic Azad University, Shahrekord; ${ }^{2}$ Department of Parasitology and Mycology, \\ School of Medicine, Isfahan University of Medical Sciences, Isfahan; ${ }^{3}$ Skin Diseases and Leishmaniasis \\ Research Center, Department of Parasitology and Mycology, School of Medicine, Isfahan University of \\ Medical Sciences, Isfahan, Iran
}

\begin{abstract}
Cystic echinococcosis (CE) is a significant zoonosis, and is endemic in some parts of the world including Iran. Hydatid cyst in Iran has been studied from different aspects and has been reported from most parts of the country. But there is no comprehensive report on the appearance of pollution in the country. This study was conducted to investigate the approximate status of infection from 1985 to 2019. In this review article, various reports on hydatid cysts were collected from 1985 to 2019. According to three criteria, i.e. the rate of infection of dogs with adult worms, the rate of infection of livestock, and the rate of infection of humans with hydatid cysts, the articles were summarized and presented to approximate the status of infection in Iran. In this study, the average infection among 11593 dogs was estimated to be $11.28 \%$. In the case of livestock, according to this review, the maximum infection of sheep was in Ardebil with $74.4 \%$, goats and cattle were in Sari with $37.8 \%$ and $40.1 \%$, camels in Khorasan Razavi with
\end{abstract}

Correspondence: Shadan Shojaat, Faculty of Veterinary Medicine, Shahrekord Branch, Islamic Azad University, P.O. Box 166, Shahrekord, Iran.

E-mail: shaadaansh@gmail.com

Key words: Iran; hydatid cyst; infection; prevalence; Echinococcus.

Acknowledgments: This article was inspired by Hassan Yousefi's $A$ review of the status of hydatid cyst infection in Iran in the years 19852005 and parts of it was translated and used.

Conflict of interest: The authors have no conflict of interest to declare.

Availability of data and materials: All data generated or analyzed during this study are included in this published article.

Ethics approval and consent to participate: Not applicable.

Received for publication: 30 November 2020.

Revision received: 21 April 2021.

Accepted for publication: 11 May 2021.

This work is licensed under a Creative Commons Attribution NonCommercial 4.0 License (CC BY-NC 4.0).

${ }^{\circ}$ Copyright: the Author(s),2021

Licensee PAGEPress, Italy

Infectious Diseases and Herbal Medicine 2021; 2:125

doi:10.4081/idhm.2021.125
$40.40 \%$, and Tabriz had the highest amount of infection in buffaloes. Out of 70907 people tested, the summary of seroepidemiological studies shows that the average infection in humans is $5.57 \%$. The information obtained from this review article shows that despite the efforts of health organizations and veterinary organizations, the rate of infection in Iran is still high compared to some countries.

\section{Introduction}

Hydatid cyst is the larval stage of the cestode worm Echinococcus granulosus (E. granulosus). ${ }^{1}$ The adult worm is in the intestines of dogs, canines, livestock, and humans (as an accidental intermediate host) and is affected by eating eggs excreted with dog feces to the Larval stage of the parasite or hydatid cyst. This disease in humans in terms of surgery and livestock due to non-consumption of infected organs can cause a lot of economic damage. The disease was widely distributed mostly in regions where sheep-rearing is a major industry. 2,3

In Iran, during the last twenty years, hydatid cysts have been studied clinically, laboratory, and epidemiologically ${ }^{4}$ and reported from different parts of the country.5,6

According to the previous systematic review, the estimated prevalence of Cystic echinococcosis (CE) in Iran was 5\%. ${ }^{7}$ The highest prevalence of CE was observed in the southwest and south of Iran. In another systematic review, the prevalence of human hydatidosis was $4.2 \%$ and the disease was most prevalent in rural regions and southern Iran. ${ }^{8}$ There is an inextricable link between human health, animal, and environmental health. This association is well represented by the revitalization of infectious zoonoses such as CE in recent years, which accounts for a major worldwide burden. So, characterization of CE prevalence among animal species involved in the transmission cycle is of utmost medical and veterinary importance. Up to now, there have been many research papers on the prevalence of CE in animal hosts in Iran, but the lack of collective data on this subject has led us to design a systematic review and meta-analysis in the country. ${ }^{7}$ In this review article, the distribution of hydatid cyst infection is collected from different parts of the country and summarized to draw the approximate status of the infection in Iran. ${ }^{9}$ Due to the weakness of the reporting system in the country, this article will not be without its drawbacks.

\section{Materials and Methods}

\section{Search Methods}

The medical publications in English and Persian electronic databases such as Google Scholar, PubMed, SID, Science Direct, and Scopus were searched from 1985 to 2019. 
The status of hydatid cyst infection in each region is determined with these three criteria: the infection rate of dogs with adult E. granulosus worms, the infection rate of cattle with hydatid cyst, and the human infection rate with hydatid cyst. Therefore, in this review article, the infection condition has been summarized and presented according to the three criteria. The subject of human infection has been presented through Seroepidemiology studies. For this purpose, published available articles (summaries or full articles) in authentic local and foreign journals have been used. To reduce the possibility of selection bias in this study, criteria were clearly defined and studied.

In articles related to the status of hydatid cyst in Iran, all available Persian papers (summaries or complete papers) have been collected through the years 1985 to 2019. The available English papers (summaries or full articles) in the hydatid cyst field in Iran have been collected from 1985 to 2019 . To achieve the rate of infection in humans we excluded case reports and studies on surgery cases. We restricted our data to seroepidemiological studies in the case of human infections.

In the discussion section of the article, to compare hydatid cyst infection in Iran and the world, one or more papers from each continent have been used as samples.

\section{Results}

In total, 110 studies met the inclusion criteria and were included in the systematic review. The study revealed that the prevalence of CE was significantly higher in the North.

\section{Results in dogs}

In the current study the highest rate of infection in dogs was seen in Kashan (55.7\%) and Sari (46.7\%) and the least was Hamadan with a $2.9 \%$ infection rate (Appnedix Table 1). ${ }^{19-51}$

\section{Results in livestock}

In the case of livestock, from the years 1985 to 2005 studies have shown that the average infection in sheep, goats, cattle, camel, and buffalo were $19 \%, 11.5 \%, 17.8 \%, 34.6 \%$, and $18.2 \%{ }^{10}$ Supported by the results of this review article through the years 2006 to 2019 the highest and lowest prevalence rates were observed in north and central Iran. According to this review, the maximum infection of sheep was in Ardebil with $74.4 \%$, goats and cattle were in Sari with $37.8 \%$ and $40.1 \%$, camels in Khorasan Razavi with $40.40 \%$, and Tabriz had the highest amount of infection in buffaloes (Appendix Table 2). ${ }^{52-61}$

Generally, the most prevalence of this disease took place in the western and southwestern areas of Iran and the highest Prevalence was related to Lorestan, Fars, and Khuzestan Provinces, and the lowest rate was related to Tehran

\section{Results in humans}

Results of this seroepidemiological review study provided that from 71485 people 5064 were seropositive in terms of Hydatid cysts infection (an average of $7.08 \%$, Appendix Table $3), 1,7,9,10,20,49,54,62-104$ while the average of seroepidemiology of hydatid cysts in Jordan, $4.2 \%$, and China 5.9 percent have been reported. In some countries, such as Greece a relatively high rate of studied cases was seropositive in terms of Hydatid cysts infection.

Indirect Fluorescent Antibody (IFA), Enzyme-Linked Immunosorbent Assay (ELISA), Counterimmunoelectrophoresis
(CIE), or Indirect Hemagglutination Assay (IHA) were used in all of the studies (ELISA was the most used test in this study).

According to the current study, the highest prevalence of infection was in Tehran province with an $18.4 \%$ infection rate, and the study was carried out by ELISA. The lowest prevalence was $0.2 \%$ in Shemiranat in Tehran; the study was carried out by IFA. The distribution map of human hydatid cyst based on seroepidemiological studies is given in Figure 1.

\section{Discussion}

\section{Infection of dogs with adult E. granulosus}

In this review study during the years, 1985-2019 thirty-seven studies in cases of dog infection have been reported in Iran. In these studies, the infection is detected by finding an adult worm $E$. granulosus in intestinal contents after autopsy or finding parasite eggs in live dog's feces.

\section{Livestock infection and infection in humans}

In this review study, thirty-eight studies were collected on the infection of livestock with hydatid cysts that occurred during the years 1985-2019 in Iran. Some cases were related to camel and buffalo infection. In these studies, the diagnosis of infection was based on finding hydatid cyst in the viscera of slaughtered animals. In this review study, only seroepidemiological studies were used.

\section{Seroepidemiological studies of hydatid cyst}

Seroepidemiological studies of hydatid cysts mainly belong to the last twenty years. During these years, sixty-seven seroepidemiological studies have been performed using different immunological tests and with different sample sizes in different parts of the country.

The study revealed that the prevalence of CE was significantly higher in the North.

In the current study the highest rate of infection in dogs was seen in Kashan $(55.7 \%)$ and Sari $(46.7 \%)$ and the least was Hamadan with a $2.9 \%$ infection rate. In the case of livestock, supported by the results of this review study the highest rates were observed in north and central Iran and the lowest prevalence was in Tehran.

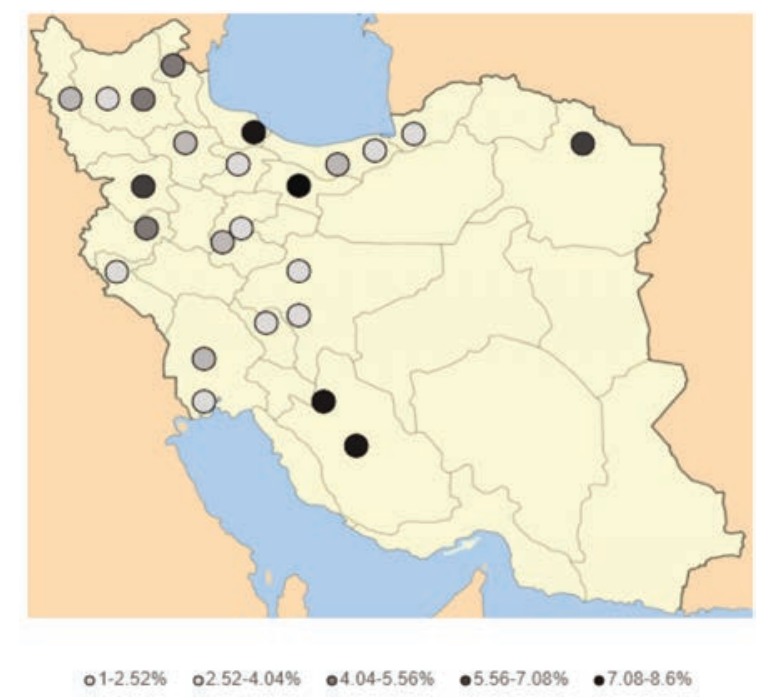

Figure 1. Human Hydatid cyst distribution based on seroepidemiological studies. 
From 1995 to 2005 in seven countries (Libya, Kenya, Iraq, Egypt, Sudan, Greece, and Queensland) mean infection rate in sheep, goats, cattle, and camels was obtained $13 \%, 5 \%, 12.3 \%$, and $37.7 \%$ respectively. ${ }^{6,11-15}$ Also, a comparison between related statistics in livestock in Iran and mentioned countries proved the high level of infection in Iran.

Generally, the most prevalence of this disease took place in the western and southwestern areas of Iran and the highest Prevalence was related to Lorestan, Fars, and Khuzestan Provinces, and the lowest rate was related to villages around Karaj and ShemiranatTehran Results of this seroepidemiological review study provided that an average of $7.08 \%$ of studied populations were seropositive in terms of Hydatid cysts infection, while the average of Seroepidemiology of hydatid cysts in Jordan, 4.2 percent $^{16}$ and China $5.9^{17}$ percent have been reported. In some countries, such as a relatively high rate of studied cases was seropositive in terms of Hydatid cysts infection.

It should be noted that in this study due to the difference in the size of the subjected populations and the period in which these studies have been done, the results can be affected. Different sample sizes, subjected populations, and time duration can affect the percentage of infection rates in different cities. In conclusion, $\mathrm{CE}$ is a major public health problem and a zoonotic parasitic disease in many countries, which results in substantial economic resource loss. Also, the different prevalence rates are due to different sensitivity and specificity of serology tests used in different studies. ${ }^{18}$

\section{Conclusions}

Hydatidosis must be considered as a dilemma in Iran in terms of health policy because of its endemicity in the country. However, one point acknowledged by nearly all researchers in the country is that the rate of human and animal cases is decreased in comparison to a decade ago.

Considering all the provided information in this article, it seems that despite effective measures that have been done by the Veterinary Organization and the health system of the country to control Hydatid cyst, the rate of this infection has been still high compared with some parts of the world. Findings of the current study revealed a relatively high rate of seropositivity to hydatid cyst in the region and indicate that $\mathrm{CE}$ is a significant health problem, especially in rural communities. Due to the importance of echinococcosis on human health and the domestic animal industry, it is necessary to monitor and control this disease in these areas. This requires public health education and awareness about the dangers of the disease and its transmission and preventive routes, education on the correct ways of animal slaughtering, prevention on feeding dogs by viscera of home-slaughtered animals, prevention on direct contact by dogs' feces, enforce legislation on meat inspection and improve veterinary services, most importantly treating and vaccination of sheep and other domestic animals, fighting stray dogs and investigation on the pollution of water and soil resources in endemic areas such as the North and West of Iran in terms of Echinococcosis' eggs.

\section{References}

1. Darani HY, Avijgan M, Karimi K, et al. Seroepidemiology of hydatid cyst in Chaharmahal va Bakhtiari Province, Iran. Iranian J Public Health 2003:31-3.

2. Moro P, Schantz PM. Echinococcosis: a review. Int J Infect
Dis 2009; 13:125-33.

3. Sadjjadi SM. Present situation of echinococcosis in the Middle East and Arabic North Africa. Parasitol Int 2006;55:S197-S202.

4. Arti H, Darani HY. Fibular hydatid cyst. Indian J Orthopaed 2007;41:244.

5. Yousofi Darani H, Hashemzadeh-Chaleshtori M, Aliyari Z, et al. Molecular characterization of the strains cause sheepHydatid cyst, in Chaharmahal va Bakhtiary province using restriction fragment length polymorphism. J Shahrekord Univ Med Sci 2007;9.

6. Saeed I, Kapel C, Saida L, et al. Epidemiology of Echinococcus granulosus in Arbil province, northern Iraq, 1990-1998. J Helminthol 2000;74:83-8.

7. Shafiei R, Teshnizi SH, Kalantar K, et al. The seroprevalence of human cystic echinococcosis in Iran: a systematic review and meta-analysis study. J Parasitol Res 2016;2016.

8. Khalkhali H, Foroutan M, Khademvatan S, et al. Prevalence of cystic echinococcosis in Iran: a systematic review and meta-analysis. J Helminthol 2018;92:260-8.

9. Rafiei A, Panabad E, Beiromvand M. The seroprevalence of cystic echinococcosis in a rural normal population, southwestern Iran. Infect Disorders-Drug Targets 2019;19:113-7.

10. Yousefi $\mathrm{H}$. A review of the status of hydatid cyst infection in Iran in the years 1364-1384. J Shahrekord Univ Sci 2008;10:78-88.

11. Chai J. Epidemiological studies on cystic echinococcosis in China--a review. Biomedical and environmental sciences: BES 1995;8:122.

12. Buishi I, Walters T, Guildea Z, et al. Reemergence of canine Echinococcus granulosus infection, Wales. Emerging Infect Dis 2005;11:568.

13. Buishi I, Njoroge EM, Bouamra O, Craig PS. Canine echinococcosis in northwest Libya: assessment of coproantigen ELISA, and a survey of infection with analysis of risk-factors. Veterinary Parasitol 2005;130:223-32.

14. Garippa G, Varcasia A, Scala A. Cystic echinococcosis in Italy from the 1950s to present. Parassitologia 2004;46:387-91.

15. Pandey V, Ouhelli H, Moumen A. Epidemiology of hydatidosis/echinococcosis in Ouarzazate, the pre-Saharian region of Morocco. Ann Tropical Med Parasitol 1988;82:461-70.

16. Moosa RA, Abdel-Hafez SK. Serodiagnosis and seroepidemiology of human unilocular hydatidosis in Jordan. Parasitol Res 1994;80:664-71.

17. Bai Y, Cheng N, Wang Q, Cao D. An epidemiological survey of cystic echinococcosis among Tibetan school pupils in West China. Ann Tropical Paediatr 2001;21:235-8.

18. El-Shazly A, Saad RM, Belal US, Sakr T, Zakae HA. Evaluation of ELISA and IHAT in serological diagnosis of proven cases of human hydatidosis. J Egypt Soc Parasitol 2010;40:531-8.

19. Maleky F, Moradkhan M. Echinococcosis in the stray dogs of Tehran, Iran. Ann Tropical Med Parasitol 2000;94:329-31.

20. Y H. A review of the status of hydatid cyst infection in Iran in 2005-2006. J Shahrekord Univ Sci 2008;10:78-88.

21. Eslami A, Hosseini SH. Echinococcus granulosus infection of farm dogs of Iran. Parasitol Res 1998;84:205-7.

22. Parviz M, Akbar AMA, Pourmohammad A. Study of infection of stray dogs with Echinococcus granulosus in Tabriz. Med J Tabriz Univ Med Sci 1989;30:57-67.

23. Dalimi A, Motamedi G, Hosseini $M$, et al. Echinococcosis/hydatidosis in western Iran. Vet Parasitol 2002;105:161-71. 
24. Da AH. Prevalence of Echinococcus granulosus infection in stray dogs in the province Mazandaran in 1989. Scientific Information Center (virtual) 2001;1:80-90.

25. Motakef M, Minou A, Lari M. An epidemiological approach to the study of echinococcosis in North-East region of Iran (Khorassan). Pahlavi Med J 1976;7:503-15.

26. Gholami S, Daryani A, Sharif M, et al. A comparison of the prevalence of Echinococcosis Granulosus in stray dogs in Sari city, in 1991 and 2007. J Mazandaran Univ Med Sci 2011;20:70-5.

27. Razmi GR, Sardari K, Kamrani A. Prevalence of Echinococcus granulosus and other intestinal helminths of stray dogs in Mashhad area, Iran. Arch Razi Institute Fall 2006;61:143-8.

28. Shariatzadeh SA, Spotin A, Gholami S, et al. The first morphometric and phylogenetic perspective on molecular epidemiology of Echinococcus granulosus sensu lato in stray dogs in a hyperendemic Middle East focus, northwestern Iran. Parasites Vectors 2015;8:409.

29. Beiromvand M, Akhlaghi L, Massom SHF, et al. Prevalence of zoonotic intestinal parasites in domestic and stray dogs in a rural area of Iran. Prev Vet Med 2013;109:162-7.

30. Dalimi A, Sattari A, Motamedi G. A study on intestinal helminthes of dogs, foxes and jackals in the western part of Iran. Vet Parasitol 2006;142:129-33.

31. Eslami A, Ranjbar-Bahadori S, Meshgi B, et al. Helminth infections of stray dogs from Garmsar, Semnan province, Central Iran. Iranian J Parasitol 2010;5:37.

32. Jahangir A, Taherikalani M, Asadolahi K, Emaneini M. Echinococcosis/hydatidosis in Ilam province, western Iran. Iranian J Parasitol 2013;8:417.

33. Emamapour SR, Borji H, Nagibi A. An epidemiological survey on intestinal helminths of stray dogs in Mashhad, Northeast of Iran. J Parasitic Dis 2015;39:266-71.

34. Mohaghegh M, Vafaei M, Ghomashlooyan M, et al. A wide diversity of zoonotic intestinal parasites in domestic and stray dogs in rural areas of Kermanshah province, Iran. Tropical Biomed 2018;35:82-90.

35. Adinezadeh A, Eshrat Beigom K, Mohebali M, et al. Endoparasites of stray dogs in Mashhad, Khorasan Razavi province, Northeast Iran with special reference to zoonotic parasites. Iranian J Parasitol 2013;8:459.

36. Sardarian K, Maghsood A, Ghiasian S, Zahirnia A. Prevalence of zoonotic intestinal parasites in household and stray dogs in rural areas of Hamadan, Western Iran. Trop Biomed 2015;32:240-6.

37. Ghabdian S, Borji H, Naghibi A. Molecular identification of Echinococcus granulosus strain in stray dogs from northeastern Iran. Vet Parasitol Regional Studies Reports 2017;9:6-8.

38. Beiromvand M, Rafiei A, Razmjou E, Maraghi S. Multiple zoonotic helminth infections in domestic dogs in a rural area of Khuzestan Province in Iran. BMC Vet Res 2018;14:224.

39. Yagoob G, Mashaei SS. Prevalence of gastrointestinal helminthic infestation in pet and stray dogs in Tabriz (EastAzerbaijan Province), Iran. J Animal Vet Adv 2011;10:14779.

40. Amouei A, Jahandar H, Daryani A, et al. Carnivores as important reservoirs of intestinal helminthic infections in Mazandaran Province, Northern Iran. Iranian J Parasitol 2018;13:251.

41. Pestechian N, Rasouli A, Yoosefi HA. Distribution of intestinal worms among stray dogs in Isfahan, Iran. J Isfahan Med School 2012;29.
42. Abdi J, Asadolahi K, Maleki MH, Ashrafi Hafez A. Prevalence of helminthes infection of stray dogs in Ilam province. J Paramed Sci 2013;4:58-61.

43. Eslahi AV, Eshrat Beigom K, Mobedi I, et al. Road killed carnivores illustrate the status of zoonotic helminthes in Caspian Sea littoral of Iran. Iranian J Parasitol 2017;12:230.

44. Keyhani A, Sharifi I, Bamorovat M, et al. Epidemiological and molecular studies on Echinococcus granulosus from freeroaming dogs in Southeast Iran. Vet World 2019;13:739.

45. Shamsi M, Dalimi A, Khosravi A, Pourahmad F. Determination and Sequencing of Genotypes of Echinococcus granulosus from Stray Dogs isolates with Cox1 Gen in Ilam, West of Iran. Sci J Ilam Univ Med Sci 2017;24:97-106.

46. Mobedi I, Zare-Bidaki M, Siavashi M, et al. Differential detection of Echinococcus spp. copro-DNA by nested-PCR in domestic and wild definitive hosts in Moghan Plain, Iran. Iranian J Parasitol 2013;8:107.

47. Keywanloo M, Hashemi Tabar G, Razmi G. Evaluation of Echinococcus granulosus coproantigens by Dot-blotting in dogs. Iranian J Vet Res 2009;10:166-71.

48. Hejazi S, Pestehchian N, Abdi J. A study of stray dog cestodes in Isfahan. J Isfahan Med School 2004;22:50-53.

49. Arbabi M, Hooshyar H. Survey of Echinococcosis and Hydatidosis in Kashan Region, Central Iran. Iran J Public Health 2006;35:75-81.

50. Beiromvand M, Akhlaghi L, Massom SHF, et al. Detection of Echinococcus multilocularis in carnivores in Razavi Khorasan province, Iran using mitochondrial DNA. PLoS Negl Trop Dis 2011;5:e1379.

51. Kohansal MH, Fazaeli A, Nourian A, et al. Dogs' gastrointestinal parasites and their association with public health in Iran. J Vet Res 2017;61:189-95.

52. Elham M, Hassan B, Ghasem NA, et al. Epidemiological study of hydatidosis in the dromedaries (Camelus dromedarius) of different regions of Iran. Asian Pacific J Trop Biomed 2014;4:S148-51.

53. Azami M, Anvarinejad M, Ezatpour B, Alirezaei M. Prevalence of hydatidosis in slaughtered animals in Iran. Turkiye Parazitol Derg 2013;37:102-6.

54. Akhlaghi L, Massoud J, Housaini A. Observation on hydatid cyst infection in Kordestan Province (West of Iran) using epidemiological and seroepidemiological criteria. Iranian J Public Health 2005:73-5.

55. Mirzaei M, Rezaei H, Nematollahi A. Role of ruminants in the epidemiology of Echinococcus granulosus in Tabriz area, Northwest of Iran. Trop Biomed 2015;32:269-75.

56. Mansoorlakooraj H, Saadati D, Javadi R, et al. A survey on hydatidosis in livestock in Northern Iran based on data collected from slaughterhouses from 2004 to 2008. Vet Parasitol 2011;182:364-7.

57. Nejad MR, Jahani-Sherafat S, Cheraghipour K, et al. Hydatic cyst prevalence in slaughtered animals, A neglected health problem. Arch Adv Biosci 2012;3.

58. Rahmani K, Radfar MH, Adinehbeigi K. Hydatidosis: prevalence and biometrical studies in sheep in Kerman area, southeast of Iran. Comparative Clin Pathol 2013;22:723-8.

59. Oryan A, Goorgipour S, Moazeni M, Shirian S. Abattoir prevalence, organ distribution, public health and economic importance of major metacestodes in sheep, goats and cattle in Fars, southern Iran. Tropical Biomed 2012;29:349-59.

60. Daryani A, Alaei R, Arab R, et al. The prevalence, intensity and viability of hydatid cysts in slaughtered animals in the Ardabil province of Northwest Iran. J Helminthol 


\section{7;81:13-7.}

61. Youssefi MR, Tabaripour R, Omrani VF, et al. Genotypic characterization of Echinococcus granulosus in Iranian goats. Asian Pacific J Trop Dis 2013;3:362-6.

62. Elahi J, Moghadam, Ghulamali. Seroepidemiological study of hydatidosis in northwestern Iran using indirect immunofluorescence method. Vet Clin Pathol (Tabriz Veterinary) 2011:1:359.

63. Dabaghzadeh H, Bairami A, Eshrat Beigom K, et al. Seroprevalence of human cystic echinococcosis in Alborz Province, central Iran in 2015. Iranian J Public Health 2018;47:561.

64. Zibaei M, Azargoon A, Ataie-Khorasgani M, et al. The serological study of cystic echinococcosis and assessment of surgical cases during 5 years (2007-2011) in Khorram Abad, Iran. Nigerian J Clin Pract 2013;16:221-5.

65. Asghari M, Mohebali M, Eshrat Beigom $\mathrm{K}$, et al. Seroepidemiology of human hydatidosis using AgB-ELISA test in Arak, central Iran. Iranian J Public Health 2013;42:391.

66. Moshfe A, Sarkari B, Arefkhah N, et al. Seroepidemiological study of cystic echinococcosis in nomadic communities in the southwest of Iran: a population-based study. J Immunoassay Immunochem 2019;40:183-92.

67. Sarkari B, Hosseini F, Khabisi SA, Sedaghat F. Seroprevalence of cystic echinococcosis in blood donors in Fars province, southern Iran. Parasite Epidemiol Control 2017;2:8-12.

68. Tavalla M, Akhlaghi L, Ourmazdi H, et al. Using Dot-ELISA method to study the prevalence of human hydatidosis in people referred to blood transfusion center in Tehran, 2005-2006. Razi J Med Sci 2010;16:52-8.

69. Mirzanejad-Asl H, Ghoreishi M, Ghahramani A, Mehmandar W. Serological and sonographical survey of hydatid disease in Moghan Plain of Iran. Res J Med Sci 2010;4:75-80.

70. Baharsefat M, Massoud J, Mobedi I, et al. Seroepidemiology of human hydatidosis in Golestan province, Iran. Iranian J Parasitol 2007:20-4.

71. Omrani VF, Rouhani S, Kazemi B, Seyyedtabaei SJ, Kheirandish F, Rezapour M. Seroprevalence of IgG antibodies against echinococcus granulosus by ELISA method using recombinant agb in Lorestan province, Western Iran. Iranian J Public Health 2017;46:1132.

72. Esmaeili N, Arbabi M. Seroepidemiology of hydatidosis among adult human at Kashan region, Iran in 2008. KAUMS Journal (FEYZ) 2010;13:321-6.

73. Rakhshanpour A, Harandi MF, Moazezi S, et al. Seroprevalence of human hydatidosis using ELISA method in Qom province, central Iran. Iranian J Parasitol 2012;7:10.

74. Sarkari B, Sadjjadi S, Beheshtian M, et al. Human cystic Echinococcosis in Yasuj district in Southwest of Iran: an epidemiological study of seroprevalence and surgical cases over a ten-year period. Zoonoses Public Health 2010;57:146-50.

75. Heidari Z, Mohebali M, Zarei Z, et al. Seroepidemiological study of human hydatidosis in Meshkinshahr district, Ardabil province, Iran. Iranian J Parasitol 2011;6:19.

76. Fathi S, Ghasemikhah $\mathrm{R}$, Mohammadi $\mathrm{R}$, et al. Seroprevalence of Hydatidosis in People Referring to Reference Laboratory of Gorgan, Golestan Province, Northern Iran 2017. Iranian J Parasitol 2019;14:436.

77. Harandi M, Moazezi S, Saba M, et al. Sonographical and serological survey of human cystic echinococcosis and analysis of risk factors associated with seroconversion in rural communities of Kerman, Iran. Zoonoses Public Health
2011;58:582-8.

78. Sharafi AC, Kheirandish F, Valipour M, et al. Seroepidemiology of human cystic echinococcosis among nomads of Lorestan province, Iran. Arch Clin Infect Dis 2018;13.

79. Youssefi MR, Mirshafiei S, Moshfegh Z, et al. Cystic echinococcosis is an occupational disease? J Parasitic Dis 2016;40:586-90.

80. Moghadam MB, Hajilooi M, Fallah M, et al. Seroprevalence of hydatidosis in outpatients attending health centers in Hamadan City, 2017. Clin Med 2018;25:99-104.

81. Esmaali Ghouraneh M, Saberi M, Farhadineko S, et al. Seroepidemiological study of hydatid cyst using AgB by ELISA in patients admitted to central laboratory of Baqiyatallah Hospital. Int J Enteric Pathog 2019;7:15-8.

82. Moradi H, Maroufi Y, Dabirzadeh M. Seroepidemiology of human hydatid cyst in Shahrebabk using ELISA. J Mazandaran Univ Med Sci 2016;25:315-8.

83. Hadadian M, Ghaffarifar F, Dalimi Asl A, Roudbar Mohammadi S. Seroepidemiological survey of hydatid cyst by ELISA in Kordestan province. Pathobiol Res 2008;10:138.

84. Manouchehri-Naeini K, Jaffari M, Kheiri S, eds. SeroPrevalence and Risk Factors of Human Hydatidosis in Chaharmahal VA Bakhtiyari Province, South West of Iran using ELISA Method, 2014-2015. Proceeding of 2th International and 9th National Iranian Congress of Parasitology and Parasitic Diseases Guilan, Iran (Abstract); 2015: p. 235.

85. Sadjjadi S, Noormohammadi A, Mohammadzadeh T, Fata A, eds. Seroepidemiological study of hydatid cyst using AgB ELISA in Torbat-Jaam, Khorasan Razavi Province, Iran. Proceeding of 2th International and 9th National Iranian Congress of Parasitology and Parasitic Diseases Guilan, Iran (Abstract); 2015: p. 228.

86. Shahrokhabadi R, Rahimi E, Poursahebi R. Seroepidemiological study of human hydatidosis in Rafsanjan, Kerman. Zahedan J Res Med Sci 2014;16:46.

87. Dadkhah MA, Yeganehzad M, Nadery B. Survey on Hydatid Cyst infestation in Sarab city (Northwest of Iran) using epidemiological and seroepidemiological criteria. J Animal Vet Adv 2011;10:2099-101.

88. GHaredagi Y, Bahavarniya S. Seroepidemiological study of hydatid cyst by ELISA method in East-Azarbaijan Province (2009). J Kerman Univ Med Sci 2011;18:172-81.

89. Kavous S, Kazemi A, Jelodari S. Seroepidemiology of human hydatid cyst in jahrom. J Jahrom Univ Med Sci 2010;8:18-24.

90. Mirzanejad-Asl H. Seroepidemiological survey of human cystic echinococcosis with ELISA method in Moghan plain, Ardabil province. J Ardabil Univ Med Sci 2009;9:334-46.

91. Moazezi S, Saba M, Kamyabi H, SHikhzadeh F. Sonographic and serological survey of hydatid disease in Rural regions of Shahdad and Chatroud, Kerman province, 2006-2007. J Kerman Univ Med Sci 2009; 15:25-34.

92. Rafiei A, Hemadi A, Maraghi S, et al. Human cystic echinococcosis in nomads of south-west Islamic Republic of Iran. EMHJ-Eastern Mediterranean Health J 2007;13:41-8.

93. Amiri Z, Massoud J, Sohrabi N, Kia E, editors. Seroepidemiological survey of human hydatid cyst in the city population of Kermanshah Province. Proceedings of national congress on hydatid cyst, Yasuj, Iran (Abstract) Armaghane Danesh J Yasuj Univ Med Sci; 2007.

94. Gholami S, Tanzifi A, Sharif M, et al. Demographic aspects of 
human hydatidosis in Iranian general population based on serology: A systematic review and meta-analysis. Vet World 2018;11:1385.

95. Farokhzad B, Nazaripouya M, Gachkar L, Mosafa N. Seroepidemiologic survey of hydatid cyst in rural area of Shemiranat and determining the efficacy of IFA test. Pajouhesh Dar Pezeshki Journal 2006;30:241-243

96. Aflaki A, Ghaffarifar F. Dalimi Asl A. Seroepidemiological survey of hydatidosis by Dot-ELISA in Ilam province. J Med Sci Modarres 2005;8:1-6.

97. Hanilou A, Badali H, Esmaeilzadeh A. Seroepidemiological study of hydatidosis in Zanjan (Islam-Abad 2002). J Adv Med Biomed Res 2004;12:41-6.

98. Yousefi H, Karimi K, Avijgan M. Seroepidemiology of Hydatid cyst in Chaharmahal and Bakhtiari province, Iran, 2000. J Shahrekord Univ Med Sci 2001;3.

99. Sedaghatghohar H, Masoud J, Rokni M. Seroepidemiologic study of human Hydatidosis in Shahriar Area: south of Tehran in 1999. J Kerman Univ Med Sci 2001;7:44-9.

100. Hosseini S, Masoud J, eds. Seroepidemiological study of hydatidosis in Divandarreh, Kurdistan and Sannandaj. Proceeding of the 3rd National Congress of Parasitology and Parasitic Disease in Iran Sari, Mazandaran, Iran; 2001.

101.Zariffard M, Abshar N, Akhavizadegan M, Motamedi G. Seroepidemiological survey of human hydatidosis in western parts of Iran. Arch Razi Institute 1999;50:71-5.

102. Arbabi M, Masoud J, Dalimi Asl A, Sajadi M. Seroepidemiologic prevalence of Hydatid cyst in Hamadan 1991. KAUMS Journal (FEYZ) 1998;2:43-50.

103. Saberi-Firouzi M, Kaffashian F, Hayati E, et al. Prevalence of hydatidosis in nomadic tribes of southern Iran. Med J The Islamic Republic of Iran (MJIRI) 1998;12:113-8.

104. Davoodi L, Kordi S, Azordeh M, Bahadori A, Bahrami F, Tabarestani M, et al. Seroprevalence of human hydatidosis and survey of risk factors in rural areas of Qaemshahr, Iran 2019. J Mazandaran Univ Med Sci 2020;30:139-45. 